\title{
Dwa projekty antynaturalizmu metodologicznego na przykładzie filozofii Heinricha Rickerta i Ernsta Cassirera
}

DOI: http://dx.doi.org/10.12775/RF.2014.020

Próba przeprowadzenia analizy porównawczej myśli kreowanej siłą umysłów dwóch czołowych przedstawicieli ruchu neokantowskiego wymaga przebadania źródłowych momentów wyodrębniania się obu filozoficznych programów z uwzględnieniem fundamentalnych czynników wpływu, które pozwalają ujawnić zarówno cechy wspólne, jak i różnicujące opisywanych projektów. Chociaż Heinrich Rickert (1863-1936) jest jednym z klasyków szkoły badeńskiej, natomiast Ernst Cassirer (1874-1945) przynależy do grona uczniów marburskiej szkoły neokantyzmu, obaj podejmują tematykę ogarniającą swym zakresem obszar rozważań dotyczących ogólnej metodologii nauk. Argumentują na rzecz metodologicznego dualizmu, upatrując różnic w badawczym postępowaniu przyrodoznawstwa i humanistyki. Każdy kroczy jednak własną drogą analiz, kreśląc samodzielny szkic metodologii, stanowiącej alternatywę dla argumentacji naturalistycznej.

Antynaturalizm metodologiczny w projekcie filozofii Rickerta uwidacznia się $w$ analizach poświęconych klasyfikacji nauk i znajduje swoje ujście w mocnym akcentowaniu opozycji natura - kultura. Dyferencja ta naznaczona jest zarówno Rickertowskim sposobem rozumienia poznania jako przekształcania rzeczywistości przez pojęcie ${ }^{1}$, jak i rozważaniami na temat problemu człowieka. Ludzkie istnienie bowiem może być rozpatrywane z perspektywy kulturowej i przyrodoznawczej; również sfera natury kształtuje obszary życia i bierze udział w dookreślaniu jego

1 Zob. A.J. Noras, Historia neokantyzmu, Wydawnictwo Uniwersytetu Śląskiego, Katowice 2012, s. 489-490. 
sensu. Dzieje się tak wówczas, gdy życie w naturze odniesiemy do sfery kultury „po to, by zyskało ono znaczenie w odniesieniu do życia ludzkiego w ogóle" ${ }^{2}$. W ten sposób nauki o przyrodzie, jako nauki o rzeczywistości, oraz nauki humanistyczne, jako nauki o kulturze, łączy wspólne królestwo sensu.

Metodologiczny antynaturalizm badawczego postępowania w filozoficznym programie Cassirera znajduje wyraz w podejmowaniu zagadnień natury matematyczno-fizycznej i historyczno-humanistycznej. Myśliciel ten, jako projektodawca kulturowego symbolizmu, zgodnie z własną - konwergentną z Rickertowską - taktyką działania, tłumaczy metodologiczny dualizm, konfirmując rozdzielenie sfery natury i kultury. Podobnie jak autor Die Grenzen der naturwissenschaftlichen Begriffsbildung, wyraźnie przeciwstawia duchową tradycję humanitas czystej postaci naturalizmu i materializmu. Jednocześnie, nadając nauce status jednej z form symbolicznych, zawiera obszar badawczych osiągnięć matematyczno-przyrodniczych w obszarze kultury, co sprawia, że „,antyteza »natury « $\mathrm{i}$ »kultury« traci swą dotychczasowa, dialektyczną ostrość" 3 .

Cassirerowska filozofia form symbolicznych, chociaż w swoim całokształcie jest jakościową metodologią nauk humanistycznych, obejmuje sobą także ilościową metodologię nauk szczegółowych. W przekonaniu Marburczyka bowiem nauka jest wchodzącym w zakres kultury przejawem wyrażania się człowieka w świecie. Chociaż metodologia poznania stricte naukowego, ograniczając się do sfery zjawisk mierzalnych, pomija składnik typowo ludzki, jest elementem kultury obejmującej szeroki zakres rozlicznych postaci ludzkiej aktywności, uwzględniających także wewnętrzną sferę człowieka ${ }^{4}$. Cassirer rozważa zatem problem człowieka w jego całokształcie, uwzględniając zarówno jego fizyczny (zewnętrzny), jak i duchowy (wewnętrzny) wymiar. W jego rozumieniu człowiek - istota biologiczna - jest również podmiotem emocjonalno-wolincjonalnym i intelektualnym; jako taki staje się jednością. Jest elementem natury i kultury zarazem.

Paralelną wykładnię człowieka zawierają nauki Rickerta. W jego przekonaniu każdy człowiek z natury uwikłany jest w pewne zależno-

2 H. Rickert, Człowiek i kultura, przeł. B. Borowicz-Sierocka, w: Neokantyzm, przeł. B. Borowicz-Sierocka i C. Karkowski, Wydawnictwo Uniwersytetu Wrocławskiego, Wrocław 1984, s. 71.

3 E. Cassirer, Logika nauk o kulturze, przeł. P. Parszutowicz, Wydawnictwo Antyk, Kęty 2011, s. 46. Zob. A. Musioł, Idea physis i anthropos w antynaturalizmie metodologicznym Ernsta Cassirera, w: Filozofia a nauki przyrodnicze. Od physis do metaphysis i anthropos, red. M. Woźniczka, A. Marek-Bieniasz, Oficyna Drukarska Jacek Chmielewski, Częstochowa 2012, s. 81-90.

4 Zob. B. Andrzejewski, Animal symbolicum. Ewolucja neokantyzmu Ernsta Cassirera, Wydawnictwo Naukowe UAM, Poznań 1980, s. 53-55. 
ści kulturowe, dlatego obszary natury i kultury wzajemnie się uzupełniają ujmując całą różnorodność form ludzkiej aktywności. Szeroko rozumiana natura, którą Rickert kojarzy z łacińskim nasci - rodzeniem się, powstawaniem, początkiem, wschodzeniem i kształtowaniem się - jest jednak również tym, w czego powstawaniu człowiek nie bierze udziału. Tu mieści się wszystko to, „,co wzrosło i powstało samo z siebie; to, co pozostawiamy jego własnemu rozwojowi" ${ }^{5}$, a więc mieści się w zakresie mogących zachodzić niezależnie od ludzkiej inicjatywy zjawisk fizycznych.

W odróżnieniu od samodzielnie rozwijającej się natury, kultura jest obszarem tego, co podlega procesowi u prawy, i jako takie wymaga ciągłej pielęgnacji. Dlatego sięgając po teorię Marcusa Tulliusa Cycerona, sferę tę Badeńczyk określa terminem colere oznaczającym pierwotnie pracę pielęgnacyjna, polową, uprawę roli, uszlachetnianie przez pielęgnację i dbanie o płody kultury ${ }^{6}$.

Wywody Cycerona inspirują również Cassirera, który łacińskie pojęcie natury - nasci - przytacza w dziele Das Erkenntnisproblem in der Philosophie und Wissenschaft der Neueren Zeit, identyfikując to pojęcie z pierwotnym znaczeniem zasady ruchu, pierwotną siłą stwarzającą i poruszającą każdą pojedynczą rzecz. Nasci zostaje ujęta w metaforę matki wszechrzeczy (Allmutter), rodzicielki i pierwszej żywicielki; w postać pierwotnego korzenia pojęcia natury (Wurzel des Naturbegriffs) ${ }^{7}$. Jako pierwotny korzeń natura wyraża się również $\mathrm{w}$ dynamice ruchu stawania się. Stawanie się natury przebiega odmiennie w stosunku do form tworzenia się kultury. W obszarze kultury, gdzie formy ludzkiej inicjatywy przyjmują postać mitu, poznania naukowego, języka, sztuki oraz religii i gdzie są różnorakimi dążeniami przekształcającymi bierne impresje w twórcze wyrazy ludzkiego ducha, mamy do czynienia z dokonującą się autorefleksja, która jest logicznym rozpatrywaniem sfery sensu. Głosząc postulat istnienia obszaru refleksji jednostki nad soba, Cassirer dowodzi, że kultura jest wynikającym z ludzkiej pracy, twórczym kształtowaniem myślowych treści ${ }^{8}$.

Ścieżka wywodu Rickerta przebiega równolegle z linią argumentacji Cassirera. Jak wcześniej zaznaczyłam, Badeńczyk przyjmuje, że kultura jest rzeczywistością specyficzną bo niesamodzielną, wykreowaną przez człowieka i stanowiącą przeciwieństwo natury; dodaje również, że o ile

5 H. Rickert, Człowiek i kultura, s. 72.

6 Zob. ibidem. Por. R. Konersmann, Filozofia kultury. Wprowadzenie, przeł. K. Krzemieniowa, Oficyna Naukowa, Warszawa 2009, s. 9.

7 E. Cassirer, Das Erkenntnisproblem in der Philosophie und Wissenschaft der Neueren Zeit, bd. 2-5, Felix Meiner Verlag, Hamburg-Berlin 2002, s. III560. s. 147.

8 J. Sójka, O koncepcji form symbolicznych Ernsta Cassirera, PWN, Warszawa 1988, 
twory natury, rozwijając się samoistnie, są przedmiotem ludzkiego zainteresowania wyłącznie jako elementy wpływające na działalność kulturowa, o tyle powstałe dzięki pracy człowieka płody kultury, jako wymagające ciągłej pielęgnacji, pozwalają urzeczywistnić się wartościom kojarzonym z wymiarem tego, co wewnętrzne - przeciwstawione naturze ${ }^{9}$. Osobliwość Rickertowskiej relacji natury i kultury ujawnia się zatem w tym, że rzeczywistość, która powstaje sama z siebie w ogólnym rozumieniu, nie przeciwstawia się sferze powstałej dzięki pracy człowieka, gdyż ta ostatnia obejmuje także zakres tego, co fizyczne. Włączenie rzeczywistości fizycznej w obszar kultury pozwala spojrzeć na różne wymiary ludzkiej aktywności in toto. W efekcie próba stworzenia na tej podstawie ogólnej definicji kultury wymaga obligatoryjnego zaangażowania szerokiego uniwersum wartości.

Dowodzą tego Rickertowskie słowa, w myśl których kultura jest ogółem dóbr chronionych ze względu na ich wartość. „Dlatego wgląd [w istotę tych dóbr - A. M.] może zyskać jedynie filozofia wartości, która poszukuje najpierw zrozumienia każdej jednostkowej dziedziny wartości w jej odrębności”10. Sama kultura jest pojęciem „zz zakresu wartości (Wertbegriff); wyjaśnienie sensu życia dotyczy problemów wartości (Wertprobleme)"11. Kultura jest zatem nie tylko - jak sądzono pierwotnie - obszarem działań ducha, lecz teraz staje się również pojęciem angażującym

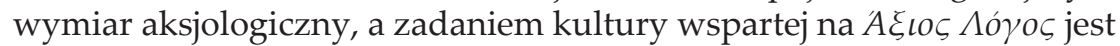
wyjaśnienie sensu ludzkiego życia. Sens ten jest podstawowym elementem Rickertowskiego systemu; medium wzajemnego porozumienia zapewniającym jedność świata; jest próbą złączenia transcendencji i immanencji w tej jedności ${ }^{12}$.

Cassirer odmiennie postrzega problem zależności kultura - wartości. Według marburczyka włączenie poszczególnych zjawisk w obszar całokształtu materialno-duchowego dorobku ludzkości, wytworzonego w ogólnym rozwoju historycznym, zależy od ich poznawczej funkcji. W związku z tym „nie geneza, nie związek z abstrakcyjnymi wartościami ani praktyczna przydatność powinna określać zakres un i w e r s u m kultury, lecz jednolita funkcja poznawcza"13. W tej relacyjnej zależności

9 Por. H. Rickert, Człowiek i kultura, s. 72-73.

10 Idem, Kant als Philosoph der modernen Kultur. Ein geschichtsphilosophischer Versuch, Akademische Verlagsbuchhandlung von J.C.B Mohr, Tübingen 1924, s. 7. Zob. A.J. Noras, Historia neokantyzmu, s. 494.

11 H. Rickert, Człowiek i kultura, s. 72, 73.

12 Ibidem, s. 75. Zob. J.K. Holzamer, Der Begriff des Sinnes, entwickelt im Anschlu $\beta$ an das "irreale Sinngebilde “ bei Heinrich Rickert, „Philosophisches Jahrbuch” 1930, nr 43, s. 325-337. Zob. T. Kubalica, Prymat rozumu praktycznego w logice. Teoria prawdy neokantowskiej szkoły badeńskiej, Wydawnictwo Uniwersytetu Śląskiego, Katowice 2009, s. $80-81$.

13 H. Buczyńska, Cassirer, Wiedza Powszechna, Warszawa 1963, s. 76. 
wyraża się symboliczny charakter kultury, która łączy wszelkie zróżnicowane względem siebie, aprioryczne zjawiska umysłu w funkcjonalną jedność. Powstałą w ten sposób gramatykę kultury porządkuje myślenie zgodne z transcendentalną logiką poznania, zebraną w formułę historycznej logiki nauk o kulturze (Kulturwissenschaften) $)^{14}$.

Według Rickerta, ranga logiki związana jest $\mathrm{z}$ formalnym badaniem specyfiki metody przyrodoznawczej, kontrastującej z wymagającą rozumienia nauką o kulturze jako nauką historyczną; wiedzą o życiu historycznym. To historia, czyniąc swoje pojęcia „wartościami ocen dotyczących stanu faktycznego"15, pozwala dokonać takiej wykładni kultury, by za jej sprawą wyznaczyć dyferencje pomiędzy mającym na względzie absolutnie obowiązującą prawdę przyrodoznawstwem a nauką o kulturze, która - wykorzystując opis historyczny - nie może postępować wyłącznie według racji czysto logicznych ${ }^{16}$. Rozwój nauk o kulturze i jakikolwiek dokonujący się w obszarze cultura postęp inspirowany jest specyficznym charakterem stanowiących go wartości, dlatego o progresie kultury decyduje stopień uświadomienia sobie systemu tych wartości ${ }^{17}$.

Cassirer z kolei wypracowaną koncepcją daje do zrozumienia, że proste zebranie faktów z zakresu ludzkiej kultury, jak również aktywność polegająca na gromadzeniu danych, ma wyłącznie empiryczno-historyczny charakter. Ujęcie filozoficzne wymaga jednak wyjścia poza tę metodologię badawczego postępowania. Filozofia w przeciwieństwie do ściśle historycznej analizy faktów, domaga się ich połączenia w funkcjonalną jedność i odniesienia do wspólnego źródła ${ }^{18}$. Tym samym to, co zmysłowe, zostaje wyartykułowane dzięki elementowi duchowemu; splot tego, co zmysłowe, z tym, co duchowe w kulturze, utrzymuje zespół logicznych zasad. Nie mniej ważną rolę odgrywa praca świadomości mediującej pomiędzy tym, co zmysłowe - naturalne, a tym, co idealne-duchowe.

O ile Rickert, mając na uwadze fakt istnienia bezimiennej i bezosobowej świadomości empirycznej, akcentuje znaczenie odniesionej do sfery ważności świadomości transcendentalnej, której rola polega na uświadamianiu sobie systemu wartości, o tyle Cassirer, uwzględniając

14 Zob. E.W. Orth, Ernst Cassirer zwischen Kulturphilosophie und Kulturwissenschaften. Ein Terminologisches Problem?, w: Lebendinge Form. Zur Metaphysik des Symbolischen in Ernst Cassirers "Nachgelassenen Manuskripten und Texten“, hrsg. R.L. Fetz, S. Ullrich, Felix Meiner Verlag, Hamburg 2008.

15 H. Rickert, Obiektywność historii kultury, w: Neokantyzm, przeł. B. Borowicz-Sierocka i C. Karkowski, Wydawnictwo Uniwersytetu Wrocławskiego, Wrocław 1984, s. 58.

16 Zob. A.J. Noras, Historia neokantyzmu, s. 481.

17 Zob. H. Rickert, Obiektywność historii kultury, s. 55-70.

18 Zob. H. Buczyńska, Cassirer, s. 77. 
znaczenie świadomości transcendentalnej, dowodzi, że jej funkcja spełnia się w procesie „nadawania kulturowego sensu temu, co doświadczane"19, a przez to także zwiększania obszaru samoświadomości. Z miejsca, z którego spogląda Cassirer, roztacza się widok na człowieka jako żywą istotę, stawiającą i realizującą własne cele w szerokim horyzoncie Geisteswissenschaften.

Stanowisko Rickerta nie odbiega od podejmowanych przez Cassirera krytycznych prób dookreślenia metodologicznej specyfiki nauk o kulturze. W zgodzie z założeniami autora Zur Logik der Kulturwissenschaften, Badeńczyk uzależnia kulturę od ludzkich celów i działań, dlatego nawet techniczne wynalazki nauk szczegółowych mają w jego przekonaniu swój udział w rozwijaniu kultury. Jej przedmiot naznaczony zostaje przez człowieka nie istniejąca, lecz obowiązującą wartościa, stąd kultura w swym całokształcie zyskuje znaczenie obszaru Allgemeinegültigkeit. Chociaż pojedynczy przedmiot kultury, jako powiązany z wartością jest przedmiotem procesu duchowego, nie może być ograniczany wyłącznie do niego. Analiza poznawcza przedmiotu kultury angażuje nie tylko proces duchowy, ale także elementy świata fizycznego, proces kulturowy bowiem odnosi się zarówno do obowiązujących wartości, jak i sfery fizyczności. Każdy z wymienionych składników procesu kulturowego duchowy, skoncentrowany na ważności wartości, a także fizyczny - bierze udział w współtworzeniu dóbr kultury ${ }^{20}$.

W przeświadczeniu Cassirera obszar kultury obejmuje zarówno wiedzę, wierzenia, sztukę, moralność, prawo, obyczaje, jak i inne zdolności nabyte przez człowieka jako członka społeczeństwa. Wszelkie tego typu dobra są wartością wynikającą z posiadania i ciągłego rozwijania umiejętności poznawczych, związanych z ulepszaniem sfery narzędziowej oraz postępem inteligencji. Specyfika kultury wyraża się zatem symbolicznie w zwyczaju i działających instytucjach. Cassirer, jako epistemologicznie zorientowany filozof kultury, opowiada się za myślnym bądź materialno-konkretnym jej tworem, jednocześnie nadaje człowiekowi status dysponującego możliwością jego uwewnętrznienia (jeśli przedmiotem kultury jest wypełniający przestrzeń twór materialny w postaci książki, kodeksu prawa, spisanego alfabetu, zasad pisowni itp.) bądź uzewnętrznienia (jeśli przedmiotem kultury jest nieposiada-

19 J. Sójka, O koncepcji form symbolicznych Ernsta Cassirera, s. 21.

20 "Halten wir also an dem mit dem Sprachgebrauch durchaus übereinstimmenden Begriff der Kultur fest, d.h. verstehen wir darunter die Gesamtheit der Objekte, an denen allgemein anerkannte Werte haften, und die mit Rücksicht auf diese Werte gepflegt werden, ohne daß wir eine nähe inhaltliche Bestimmung hinzufügen, und sehen wir nun zu, wie dieser Begriff uns weiter zur Abgrenzung der zwei Gruppen von Wissenschaften dienen kann॰. Zob. H. Rickert, Kulturwissenschaft und Naturwissenschaft, Akademische Verlagsbuchhandlung von J.C.B. Mohr, Tübingen 1915, s. $18-28,53-57$. 
jący charakteru przestrzennego wytwór pracy ducha, np. świadomość zasad etycznych, świadomość technik liczenia, świadomość wartości rozbudzających potencjał intelektualny i artystyczny) ${ }^{21}$.

Poglądy Rickerta współbrzmią z założeniami stanowiska Cassirerowskiego i są wyrazem przekonania, że rzeczywistość w swoim całokształcie może zostać ujęta w dwojaki sposób, gdyż dzieli się albo na taka, która wypełnia przestrzeń fizyczna, albo taka, która jej nie wypełnia, ponieważ nie ma charakteru fizyczno-materialnego. Możemy zatem mówić albo o pewnych wielkościach fizycznych - policzalnych, albo o niedającej się zmierzyć jedności świadomości i na tej podstawie dokonać rozdzielenia nauk na przyrodnicze (nauki prawne; Gesetzwissenschaften) oraz humanistyczne (nauki wydarzeniowe; Ereigniswissenschaften). O ile nauki przyrodnicze to nauki o rzeczywistości fizycznej, o tyle nauki humanistyczne, jako nauki o kulturze, stanowią o rzeczywistości nadmaterialnej.

Rickert, sprowadzając swoje rozważania na płaszczyznę dualistycznego rozdziału nauk, nazywa metodę wypełniających przestrzeń fizyczną nauk przyrodniczych metodą generalizującą (uogólniającą) i dowodzi, że w generalizowaniu (uogólnianiu) ukrywa się jej logiczna istota, wynikająca z logicznej struktury przyrodoznawstwa; z kolei metodę niefizycznych nauk humanistycznych określa mianem metody indywidualizującej. Ujawniający się bipolarny podział dziedzin wiedzy pozwala skojarzyć nauki szczegółowe ze sferą logiczną i metodą uogólniającą bądź też każe badającemu oprzeć się na metodologii indywidualizującej, nakazującej ująć analizowaną materię wyłącznie w formę historii kultury22.

W odróżnieniu do Rickerta, Cassirer poszukuje logicznego myślenia nie tylko w obszarze nauk przyrodniczych. Poszerzając projekt teoretycznej filozofii Immanuela Kanta, rozpisuje program badań nad logiką nauk o kulturze. Wyraża aprioryczną koncepcję kulturowego panlogizmu, który realizując się jako system sensu, decyduje o sposobie organizacji świata. Jest strategią kreacji sfery intelektualnej i budowania znaczeń, a jednocześnie stanowi trwałe świadectwo przebudowy Kantowskiej krytyki rozumu w krytykę kultury ${ }^{23}$.

W systemie Rickerta obszarami świata natury zajmują się nauki szczegółowe, dysponujące klarowną strukturą pojęciową. Nauki przyrodnicze, odwołując się do powszechnego pojęcia, wymagają zasady

21 Zob. Słownik filozofii, red. A. Aduszkiewicz, Świat Książki, Warszawa 2004, s. 98-99.

22 Por. H. Rickert, Tezy do systemu filozofii, przeł. B. Borowicz-Sierocka, w: Neokantyzm, s. 48-49. Zob. A.J. Noras, Historia neokantyzmu, s. 493. Zob. I. Dąmbska, Kilka uwag w sprawie wartości poznawczych, „Znak” 1965, nr 4, s. 439-445.

23 Stownik filozofii, s. 100. 
przewodniej. To nauki warunkowane regułą prawa, sygnowane powtarzalnością i wielokrotnością. Tak ujęte potwierdzają swój generalizujący (uogólniający) charakter. Sferę nauk humanistycznych natomiast stanowi obszar zjawisk niepowtarzających się, zindywidualizowanych: opisujących fakty jednokrotne i niepowtarzalne. Oddzielenie przyrodniczego - skupionego na formułowaniu praw - oraz historyczno-humanistycznego - wzmacniającego aspekt jednorazowości - porządku badawczego postępowania znajduje swoją pierwotną postać w Windelbandowskim rozdziale nauk na nomotetyczne i idiograficzne ${ }^{24}$.

Cassirer podaje w wątpliwość słuszność badeńskiej propozycji rozdziału nauk. Jego wątpliwości budzi również proponowana przez szkołę Wilhelma Windelbanda teoria wartości. Postawa krytyczna i wynikająca z niej metoda dowodzenia pozwala zatrzeć ostro zarysowaną granicę, rozdzielającą nauki przyrodoznawczo-uniwersalne od historyczno-indywidualizujących. W wyniku tego obszar nauk przyrodoznawczych ujawnia problemy wymagające zaangażowania metodologii historycznej, z kolei nauki historyczne stosują elementy przyrodoznawczej metody analiz, twierdzi Cassirer. Dlatego, za sprawą rozdziału Rickerta, „zamiast dwóch jasno oddzielonych skrajności najczęściej otrzymujemy tylko jakieś formy mieszane i przejściowe. Zgodnie z teorią Rickerta każde poznanie tego, co historyczno-indywidualne, zawiera swoje odniesienie do tego, co ogólne" 25 .

Cassirer zauważa, że w indywidualizujących naukach historycznych wszelka ogólność wymaga, według Rickerta, odniesienia do systemu uniwersalnych wartości. W związku z tym stwierdza, że Windelband oraz Rickert, jako adherenci filozofii Kanta, „chcą zrobić dla historii i nauki o kulturze to, co Kant zrobił dla matematycznego przyrodoznawstwa" ${ }^{26}$. Stąd wynika m.in. ich odniesienie do ogólnego systemu wartości. Jednak czyniąc ogólny system wartości warunkiem możliwości

24 „In neuester Zeit ist denn auch der Gegensatz des naturwissenschaftlichen und des historischen Verfahrens wenigstens nach dieser einen, des historischen Verfahrens wenigstens nach dieser einen, wenn auch gewissermaßen nur negativenSeite hin vollkommen klar gemacht. Die Unterscheidung von Gesetzes- und Geisteswissenschaften bei Paul habe ich bereits erwähnt. Ohne auf die übrigen Beiträge zur Klarlegung dieses Punktes einzugehen, weise ich hier nur auf die Ausführungen Windelbands hin. Er stellt neben das "nomothetische« Verfahren der Naturwissenschaft das »idiographische« der Geschichte als dasjenige, welches auf die Darstellung des Einmaligen und Besonderen gerichtet ist, und der Einschränkung, daß das nomotchetische Verfahren nicht nur auf die Auffindung von Gesetzen im strengsten Sinne, sondern auch auf die Bildung von empirisch allgemeinen Begriffen bezogen Bildung von Empirisch allgemeinen Begriffen bezogen werden von empirisch allgemeinen Begriffen bezogen werden muß, ist dies zweifellos richtig". Zob. H. Rickert, Kulturwissenschaft und Naturwissenschaft, s. 58-59.

25 E. Cassirer, Logika nauk o kulturze, s. 61.

26 Ibidem, s. 62. 
poznania w naukach humanistycznych, Rickert wikła się - przekonuje Cassirer - w ciąg trudności: jak bowiem historyk dociera do takiego systemu wartości i ugruntowuje go, nadając mu obiektywną ważność? W konsekwencji Marburczyk przyjmuje, że sam tylko historyczny punkt widzenia jest niewystarczający i grozi uwikłaniem w logiczne błędne koło, natomiast próba apriorycznego skonstruowania systemu wartości wymaga przyjęcia metafizycznego założenia, co sprawia, że Rickert wraca w swych rozstrzygnięciach do punktu wyjścia ${ }^{27}$.

W horyzoncie dzielących obu filozofów różnic ujawniają się elementy wiążące. Po pierwsze, chętnie akcentowane przez Rickerta przeciwieństwo historycznego ducha i fizycznego ciała sprowadza się do metodologicznej różnicy pomiędzy humanistycznymi naukami o kulturze i empirycznymi naukami o przyrodzie. Takiego rozdziału nauk świadomy jest Cassirer. Po drugie, spójność poglądów potwierdza fakt, że obaj treści przyrodoznawcze uchwytują kwantytatywnie, natomiast teorię nauk humanistycznych traktują jako opisującą to, co kwalitatywne ${ }^{28}$.

Odmienność stanowisk leży w szczegółach. Rickert tłumacząc, że sfera nauk humanistycznych wiąże się z wartościami, suponuje, że tylko przy udziale określonego kompleksu wartości ujawnia się całościowy sens świata, który podlega rozumieniu pod warunkiem sine qua non: bycia określonym $\mathrm{w}$ systemie tych wartości ${ }^{29}$. Przedmiotem zainteresowania Cassirera natomiast nie jest Rickertowski świat w ogóle, lecz sposoby ludzkiego budowania wiedzy o świecie; strategie kształtowania ludzkiego wyobrażenia na temat świata. O ile zatem nauki szczegółowe (przyrodoznawstwo) dają wiedzę, która wchodzi w zakres naukowego obrazu świata, kreowanego pracą naukowca, o tyle mit kształtuje obraz świata widziany oczyma człowieka pierwotnego, religia kształtuje rzeczywistość w relacji Bóg - człowiek, język formułuje, uchwytując czasoprzestrzennie i liczbowo przy wykorzystaniu elementu zmysłowo-znaczeniowego, sztuka natomiast jest obszarem, w którym człowiek wyraża świat poprzez artystyczny twór. Te wyróżnione przez Cassirera sfery ludzkiej aktywności mają charakter funkcjonalny ${ }^{30}$.

Różnica między pojęciami funkcji i substancji jest mocno akcentowana w filozofii Cassirera. Także Rickert podejmuje zadanie jej naukowej deskrypcji. Jego zdaniem, fizyczno-matematyczne pojęcia grawitacji i prawa ciążenia, chociaż są pojęciami relacyjnym (Relationsbegriffe), nie rzeczowymi (Dingbegriffe), zakładając kategorię ciążącej masy, impliku-

\footnotetext{
Ibidem.

Zob. H. Rickert, Kulturwissenschaft und Naturwissenschaft, s. 128-131.

29 Ibidem, s. 148.
}

30 Zob. E. Cassirer, Substancja i funkcja. Badania nad podstawowymi problemami krytyki poznania, przeł. P. Parszutowicz, Wydawnictwo Marek Derewiecki, Kęty 2008, s. 255 . 
ją pojęcie res. Chociaż rozdzielenie wyróżniającej się na gruncie teoriopoznawczym relacji i obecnej w rozważaniach dotyczących teorii bytu rzeczy jest konieczne, to transcendentalnie usankcjonowana nauka wymaga włączenia w swoje rozstrzygnięcia zarówno pierwszego, jak i drugiego pojęcia ${ }^{31}$.

Obaj filozofowie dowodzą tym samym, że ich logiczno-transcendentalny program obejmuje rozważania natury epistemologicznej i ontologicznej. W projekcie Cassirera nauka, tłumacząc rzeczywistość, jest teorią poznania, natomiast kulturowe a priori, pełniąc funkcję rzeczywistościotwórcza, przyjmuje postać ontologii mitycznej, religijnej, artystycznej, językowej, ogarniając swym zakresem szeroką gamę obszarów ludzkiej aktywności ${ }^{32}$. O ile Cassirer tworzy antropologiczny projekt morfologii kultury, o tyle Rickert pisze o konieczności ujęcia poszczególnych składników świata, które pozwalają określić go w jego ontologicznym pluralizmie, obejmującym wielość bytów ${ }^{33}$. Pluralistyczna ontologia Rickerta, zawierając w sobie

wielorako rozczłonkowany byt [pozwala] stworzyć [filozofię jako] naukę o sensie życia ludzkiego. Filozofia ta ma pytać nie tylko o byt świata w ogóle, lecz powinna stawiać również pytania o charakterze szczegółowym, dotyczące postawy człowieka w świecie i wobec świata. Dopiero na bazie tak rozległej ontologii może ona stworzyć naukową antropologię filozoficzną, która wychodzi od człowieka jako całości, aby dojść do rozważań natury uniwersalnej. One w pełni obnażają filozofię jako naukę o wartościach ${ }^{34}$.

Rickert, czyniąc centralną kategorią swojej filozofii pojęcie obowiązującej wartości, rozwija wiedzę na temat nauk humanistycznych, przy jednoczesnym odniesieniu do nauk szczegółowych. Postulat uwzględnienia wartości jako podstawy każdego filozoficznego systemu, staje się

31 „Zugegeben, dass der Begriff der Gravitation identisch ist mit dem Gravitationsgesetz, so ist er es nur darum, weil er kein Dingbegriff, sondern ein Relationsbegriff ist. Auch er setzt aber stets gravitierende Massen, also Dingbegriffe voraus, so gut wie der früher als Beispiel bereits erwähnte Begriff der Ehe Mann und Weib voraussetzen musste. Unsere Theorie würde demnach nur für die Relationsbegriffe gelten. Die Dingbegriffe könnten niemals zu logisch vollkommenen Begriffen in unserem Sinne gemacht werden, obwohl sie doch nothwendige Voraussetzungen der Relationsbegriffe sind - Ist dieser Einwand nicht berechtigt?" Zob. H. Rickert, Die Grenzen naturwissenschaftlichen Begriffsbildung. Eine logische Einleitung in die historischen Wissenschaften, Akademische Verlagsbuchhandlung von J.C.B. Mohr, Freiburg-Leipzig 1896, s. 75-78.

${ }_{32}$ Zob. J. Sójka, O koncepcji form symbolicznych, s. 10.

33 Por. H. Rickert, Tezy do systemu filozofii, przeł. B. Borowicz-Sierocka, w: Neokantyzm, s. $45-48$.

34 Ibidem, s. 51. 
w jego programie „metodologicznym warunkiem produktywności badań wytworów kultury i zdarzeń historycznych, [...] co jest najbardziej adekwatnym ujęciem specyfiki humanistyki jako nauki" ${ }^{35}$. Filozof ten, podobnie jak Cassirer, wchodzi w dyskusję toczącą się wokół swoistości procesu poznania, dokonującego się w obrębie wiedzy wykraczającej swym zasięgiem poza czyste przyrodoznawstwo. Uwzględniając dywergencje $\mathrm{w}$ obszarze metodologii nauk, potwierdza, że jego filozofia jest metodologicznym antynaturalizmem. Tymczasem Cassirer prezentuje się jako zwolennik antynaturalizmu ontologicznego i metodologicznego. Jako antynaturalista ontologiczny „broni swoistości ontycznej obiektów humanistycznych, np. wartości, języka, mitu, umysłu"36, natomiast zgodnie z przekonaniami antynaturalistów metodologicznych, nie wypowiada się „,na temat statusu ontologicznego [takich obiektów, głosząc jedynie], że istnieją swoiste dla humanistyki sposoby ich badania i rozumienia. Tą szczególną i swoistą procedurą badawczą humanisty jest interpretacja humanistyczna" ${ }^{37}$. Odróżniając wyraźnie przyrodoznawczy i humanistyczny tryb postępowania, także Cassirer potwierdza, że jego projekt filozofii jest metodologicznym dualizmem.

\section{Streszczenie}

\section{Dwa projekty antynaturalizmu metodologicznego na przykładzie filozofii Heinricha Rickerta i Ernsta Cassirera}

\section{Słowa kluczowe}

Neokantyzm; Cassirer; Rickert; antynaturalizm metodologiczny; filozofia kultury

Dwaj filozofowie przełomu wieków, Heinrich Rickert (1863-1936) oraz Ernst Cassirer (1874-1945) przynależą do licznego i niejednoznacznego w swych poglądach, ruchu neokantystów. Chociaż filozofia Immanuela Kanta stanowi dla obydwóch niepodważalną bazę - fundament rozważań, pomiędzy teorią autora trzech Krytyk a neokantyzmem ujawnia się różnica zakresu bowiem o ile transcendentalizm Kanta ma charakter ogólny, o tyle na gruncie badeńskiej szkoły neokantyzmu, której reprezentantem jest Rickert, dokonuje się jego uszczegółowienie. Stawiając problem apriorycznych warunków możliwości poznania, Rickert podejmuje próbę transcendentalnego ugruntowania kultury. Poszuku-

35 A. Przyłębski, W poszukiwaniu królestwa filozofii. Z dziejów neokantyzmu badeńskiego, Wydawnictwo Naukowe UAM, Poznań 1993, s. 41.

36 Stownik filozofii, s. 98.

37 Ibidem, s. 98-99. 
jąc podstawy poznania i kultury w ogóle, przyjmuje Windelbandowski podział nauk na uogólniające nauki nomotetyczne i indywidualizujące nauki idiograficzne oraz nazywa historię warunkiem możliwości doświadczenia. Jako reprezentant dualizmu metodologicznego myśliciel ten czyni filozofię, krytyczną teorią wartości kulturowych. Włączając w zakres metodologicznych rozstrzygnięć zagadnienia aksjologiczne, wśród których na pierwszy plan wysuwa zagadnienie nadających życiu sens wartości oraz tego, co koniecznie ważne, Rickert nie tylko dookreśla poprzez to właściwy przedmiot poznania, ale także myślenie teoretyczne zakorzenia $\mathrm{w}$ powinności, natomiast poznanie ugruntowuje w czystej logice obowiązywania (Geltung).

Zagadnienie logicznych podstaw nauk o duchu, rozpatrywanych z perspektywy krytycznej filozofii kultury, bada również uczeń marburskiej szkoły neokantyzmu, Ernst Cassirer. Swoje zainteresowania naukami przyrodniczymi, zwłaszcza fizyką matematyczna, wzbogaca szeroko rozumianą koncepcją kultury zakładając, iż nauki o przyrodzie i humanistyka jako decydujące o całej aktywności człowieka, nie są sobie przeciwstawne, lecz wzajemnie się uzupełniają. Wiążąc mierzalny - ilościowy i wolicjonalno-emocjonalny - jakościowy moment aktu poznania, Cassirer rezygnuje z zaproponowanej przez badeńczyków (Windelband, Rickert) teorii wartości oraz podziału nauk. Dostrzegając ludzką zmienność, skupia się na historyczno-humanistycznym opisie różnorodnych form ludzkiego życia.

Ukazując pierwotny związek myśli Cassirera i Rickerta z teoretyczną oraz praktyczną nauką Kanta, w wystąpieniu zwracam szczególną uwagę na przebieg linii demarkacyjnej rozdzielającej sferę Geisteswissenschaften od obszaru Naturwissenschaften $\mathrm{w}$ zaproponowanych przez neokantystów programach filozofii. Wykorzystując metodę analizy porównawczej, charakteryzuję sposób ujęcia przyrodoznawstwa oraz nauk o kulturze, który w filozofii Rickerta wyraża się $\mathrm{w}$ różnicy: nasci - colere, natomiast $\mathrm{w}$ myśli Cassirera przyjmuje postać rozdzielenia: fakt nauki - fakt kultury; dywergencji, która ujawnia się pomiędzy tym, co kwantytatywne a tym, co kwalitatywne.

\section{Summary}

\section{Two projects of methodological antinaturalism follow the lead of Heinrich Rickert's and Ernst Cassirer's philosophy}

\section{Keywords}

Neo-Kantianism; Cassirer; Rickert; methodological antinaturalism; philosophy of culture

Two philosophers of turn of the century, Heinrich Rickert (1863-1936) and Ernst Cassirer (1874-1945) belong to large and not identical in meaning in their own views, the Neo-Kantianism movement. Though the Immanuel Kant's phi- 
losophy to the state for both the irrefutable base - the foundation of considerations, among the theory of author of three Critiques and neo-Kantianism comes to light the difference of the range as far as Kant's transcendentalism has the general character, insomuch aground Southwestern neo-Kantianism whose a representative is Rickert, takes place his particularization. There placing the problem of a priori conditions of possibility of the recognition, Rickert undertakes an attempt of the transcendental basis of the culture. Seeking bases of the recognition and the culture whatever, accepts Windelband's partition of knowledge on generalizing nomothetic's disciplines (the sciences) and individualizing idiographic's disciplines (the humanities) and calls the history a condition of the possibility of the experience. As the representative of the methodological dualism this thinker makes the philosophy, with the critical theory of cultural values. To include into the range of methodological decisions of the axiological problem among which to the foreground advances the problem granting the life the sense of the value and this, what necessarily important, Rickert not only additionally qualifies across this the proper object of the recognition, but also the theoretical thinking implants in the duty, instead the recognition establishes in the pure logic of being obligatory (Geltung).

The problem of logical bases of disciplines about the spirit, examined from the perspective of the critical philosophy of the culture, investigates also the schoolboy of the Marburg neo-Kantianism, Ernst Cassirer. Its own interests with sciences, especially with the mathematical physics, he enriches with the widely understood idea of the culture founding, that sciences about the nature and the humanities as decisive about the all activity of the man, are not to themselves opposed, but mutually are complementary to one another. Binding measurablequantitative and volitional and emotional - the qualitative moment of the act of the recognition, Cassirer throws up proposed by Baden school (Windelband, Rickert) of the theory of the value and the partition disciplines of knowledge. Perceiving the human variability, one assembles on historic and humanistic description of various forms of the human life.

Showing the primary relationship of the Cassirer's and Rickert's thought with theoretical either with the practical Kant's knowledge, in the pronouncement I return the special attention on the course of the line of demarcation dividing the sphere Geisteswissenschaften from the area Naturwissenschaften in proposed by neo-Kantian programs of the philosophy. Using the method of the comparative analysis, I characterize the manner of the seizure of the sciences and humanities - knowledge about the culture in Rickert's philosophy expresses himself in the difference: nasci - colere, instead inwards Cassirera accepts the form of the disjunction: fact of the science - fact of the culture; difference which comes to light among this, what quantitative and to these, what qualitative.

\section{Bibliografia}

Andrzejewski B., Animal symbolicum. Ewolucja neokantyzmu Ernsta Cassirera, Wydawnictwo Naukowe Uniwersytetu Adama Mickiewicza, Poznań 1980.

Buczyńska H., Cassirer, Wiedza Powszechna, Warszawa 1963. 
Cassirer E., Das Erkenntnisproblem in der Philosophie und Wissenschaft der Neueren Zeit, bd. 2-5, Felix Meiner Verlag, Hamburg-Berlin 2002.

Cassirer E., Logika nauk o kulturze, przeł. P. Parszutowicz, Wydawnictwo Antyk, Kęty 2011.

Dąmbska I., Kilka uwag w sprawie wartości poznawczych, "Znak” 1965, nr 4, s. $439-445$.

Holzamer J.K., Der Begriff des Sinnes, entwickelt im Anschlu $\beta$ an das „irreale Sinngebilde" bei Heinrich Rickert, „Philosophisches Jahrbuch” 1930.

Konersmann R., Filozofia kultury. Wprowadzenie, Oficyna Naukowa Warszawa, Warszawa 2009.

Kubalica T., Prymat rozumu praktycznego w logice. Teoria prawdy neokantowskiej szkoły badeńskiej, Wydawnictwo Uniwersytetu Śląskiego, Katowice 2009.

Musioł A., Idea physis $i$ anthropos w antynaturalizmie metodologicznym Ernsta Cassirera, w: Filozofia a nauki przyrodnicze. Od physis do metaphysis $i$ anthropos, red. M. Woźniczka, A. Marek-Bieniasz, Oficyna Drukarska Jacek Chmielewski, Częstochowa 2012.

Noras A.J., Historia neokantyzmu, Wydawnictwo Uniwersytetu Śląskiego, Katowice 2012.

Neokantyzm, przeł. B. Borowicz-Sierocka i C. Karkowski, Wydawnictwo Uniwersytetu Wrocławskiego, Wrocław 1984.

Orth E.W., Ernst Cassirer zwischen Kulturphilosophie und Kulturwissenschaften. Ein Terminologisches Problem?, w: Lebendinge Form. Zur Metaphysik des Symbolischen in Ernst Cassirers "Nachgelassenen Manuskripten und Texten”, hrsg. R.L. Fetz, S. Ullrich, Felix Meiner Verlag, Hamburg 2008.

Przyłębski A., W poszukiwaniu królestwa filozofii. Z dziejów neokantyzmu badeńskiego, Poznań 1993.

Rickert H., Die Grenzen naturwissenschaftlichen Begriffsbildung. Eine logische Einleitung in die historischen Wissenschaften, Freiburg-Leipzig 1896.

Rickert H., Kant als Philosoph der modernen Kultur. Ein geschichtsphilosophischer Versuch, J.C.B. Mohr, Tübingen 1924.

Rickert H., Kulturwissenschaft und Naturwissenschaft, J.C.B. Mohr, Tübingen 1915.

Rickert H., Tezy do systemu filozofii, przeł. B. Borowicz-Sierocka, w: Neokantyzm, przeł. B. Borowicz-Sierocka, C. Karkowski. Wydawnictwo Uniwersytetu Wrocławskiego, Wrocław 1984.

Słownik filozofii, red. A. Aduszkiewicz, Świat Książki, Warszawa 2004.

Sójka J., O koncepcji form symbolicznych Ernsta Cassirera, Państwowe Wydawnictwo Naukowe, Warszawa 1988. 